\title{
Impact of contrasting fish oil concentrations in the diet on ovine embryo development in vivo and of corresponding diet-specific derivative sera during in vitro culture*
}

\author{
T.G. McEvoy ${ }^{1}$, A.G. Onal ${ }^{1,2}$, B.K. Speake ${ }^{1}$ and J.J. Robinson ${ }^{1,3}$ \\ ${ }^{1}$ Sustainable Livestock Systems Research Group, Scottish Agricultural College \\ West Mains Road, Edinburgh, EH9 3JG, Scotland, United Kingdom
}

(Received 13 August 2011; revised version 14 December 2011; accepted 12 March 2012)

\begin{abstract}
In the first of two experiments, numbers of ovulations and day 5 embryo yields were unaffected by fish oil $(0,3$ or $6 \% \mathrm{w} / \mathrm{w})$ in ewe diets; oestradiol concentrations and numbers of large ovarian follicles were increased. Fish oil tended to suppress embryo development and limit blastocyst diameter and cell number but not protein synthesis. In the second experiment IVF-derived embryos were cultured in medium supplemented with foetal calf serum (FCS) or, as in vitro equivalents to Experiment 1, serum from ewes fed rations supplemented with $0(\mathrm{C}), 3(3 \mathrm{~F})$ or $6(6 \mathrm{~F}) \%$ fish oil. Cleavage rates were not affected by serum source. More Grade 1 to 1.5 blastocysts were produced when using $3 \mathrm{~F}$ serum $(32 \%$ of blastocysts) than with $\mathrm{C}(27 \%$; ns) or $6 \mathrm{~F}(16 \% ; \mathrm{P}<0.05)$ or $\mathrm{FCS}(10 \%$; $\mathrm{P}<0.005)$. It is suggested that at less than $3 \%$ inclusion in the diet of ewes, there may be beneficial effects of fish oil fatty acids on embryo production in vivo and of the corresponding ewe serum during in vitro culture. Higher concentrations are counter-productive.
\end{abstract}

KEY WORDS: fish oil, ovulation rate, oocytes, embryos, antioxidants, sheep

\footnotetext{
* Supported by the Scottish Government. Rations, formulated to the authors' specification, were donated by Harbro Limited, Aberdeenshire, Scotland. A.G. Onal was supported financially by the Turkish Ministry of Education

2 Present address: Department of Animal Science, Faculty of Agriculture, Mustafa Kemal University, Antakya, Hatay Province, Turkey

3 Corresponding author: email: john.robinson@sac.ac.uk
} 


\section{INTRODUCTION}

The quality of oocytes and early cleavage-stage embryos is important in the successful establishment of pregnancy and the birth of viable neonates. This holds true for natural pregnancies, those established following multiple ovulation and embryo transfer, and those involving the use of in vitro embryo production techniques. In all cases feeding level and diet composition can have effects on the oocyte that influence early embryo development. These effects can, however, differ between the embryo production techniques (Robinson et al., 2006). For example, high plane feeding improved oocyte quality in spontaneously-ovulating ewes but decreased it in superovulated ewes (McEvoy et al., 1995; Lozano et al., 2003). Using non-lactating beef $x$ dairy heifers Adamiak et al. (2005) found that while high plane feeding reduced the quality of oocytes aspirated from animals in good body condition it increased it among those from heifers in poor condition.

In terms of diet composition, dietary excesses of proteins that are rapidly degraded in the rumen appear to have more damaging effects on the developmental capabilities of aspirated oocytes and oocytes from gonadotrophin-stimulated follicles than those arising from spontaneous ovulations (reviewed by Robinson et al., 2006). The nature of the dietary energy source has also been shown to be important, with high-starch concentrate diets that are rapidly fermented in the rumen having an adverse effect on the quality of oocytes from superovulated beef heifers (Yaakub et al., 1999) and from moderately stimulated beef $\mathrm{x}$ dairy heifers of low body condition (Adamiak et al., 2006).

In the context of the present investigations on fatty acids, the literature on their role as energy providers for the oocyte and early embryo points to their use from both endogenous and exogenous sources (Sturmey et al., 2009). Dietary lipid supplements have been shown in numerous studies (Staples and Thatcher, 2005) to improve dairy cow fertility either through the correction of an essential fatty acid deficiency or via an enhancement of the endocrine and immune systems. Evidence that they have a beneficial effect on the oocyte and early embryo is equivocal. Against the background that negative energy balance and its accompanying mobilization of large amounts of body fat impair oocyte quality (Kruip et al., 2001) the addition of fatty acids, of the type (non-esterified) circulating in the animal's blood and ovarian follicular fluid during negative energy balance, to in vitro embryo culture medium, has been shown to delay oocyte maturation and impair blastocyst production (Jorritsma et al., 2004; Leroy et al., 2005). Also, supplementation of the diet of beef $x$ dairy heifers that were in low body condition with $6 \%$ lipid (calcium soap of palm oil) reduced the post-fertilization development of their aspirated oocytes (Adamiak et al., 2006). There are other reports, however, of beneficial effects of fatty acids. For example Fouladi-Nashta et al. $(2004,2007)$ 
found that supplementing the diet of high-yielding dairy cows with 800 as opposed to $200 \mathrm{~g}$ /day of a calcium soap of palm oil improved the quality of aspirated oocytes and their post-fertilization in vitro development into blastocysts. In ewes, Cancino-Arroyo et al. (2006) recorded a significant improvement in the quality of oocytes aspirated from gonadotrophin-stimulated follicles and a tendency towards better in vitro maturation, fertilization and embryo development when the diet was supplemented with $4 \%$ maize oil.

Bilby et al. $(2005,2006)$ reported that dairy cows given a diet enriched with linoleic acid tended to yield aspirated oocytes with a subsequently slower rate of in vitro embryo development than those from cows given an oleic acid-enriched diet. Linoleic acid supplementation of an in vitro culture medium (Marei et al., 2010) confirmed its inhibitory effect on bovine oocytes and early embryos. In contrast, the same group had previously found that supplementation with $\alpha$-linolenic acid enhanced maturation rate and increased bovine blastocyst yield (Marei et al., 2009). In a recent study by Al Darwich et al. (2010) enhanced in vitro bovine embryo survival was also obtained with linolenic acid supplementation compared with that achieved in presence of either conjugated linoleic acid (CLA) or docosahexaenoic acid. While conjugated fatty acids are a special case due to their various and intriguing biological influences, they are not a focus for the present study. Nevertheless, it is notable that trans-10 cis-12 CLA has been reported to improve viability of biopsied and vitrified bovine embryos (Pereira et al., 2008) and, most recently, to have significant effects on bovine oocyte competence and fatty acid composition (Lapa et al., 2011).

Observations recorded for embryo quality at five (Cerri et al., 2004, 2009) and seven (Thangavelu et al., 2007) days after insemination, and for embryo survival (Petit and Twagiramungu, 2006) and conception rate to first insemination (Juchem et al., 2004, 2010) support the finding that, for the oocyte and early embryo, some fatty acids among the polyunsaturates, in particular linolenic, are superior to others.

Despite reports of the beneficial effect of fish meal on reproduction in dairy cows (reviewed by Staples and Thatcher, 2005) and the rich source that fish oil is of the long-chain n-3 polyunsaturated fatty acids, eicosapentaenoic (EPA; C20:5) and docosahexaenoic (DHA; C22:6) which are renowned for their beneficial effects on human and animal health, there is very little information on their specific effects on the oocyte and early embryo. Yet, given the beneficial effect on oocyte maturation and early embryo development of $\alpha$-linolenic acid, which is a precursor of EPA and DHA, it is reasonable to anticipate that, provided there is adequate antioxidative protection, there may be specific beneficial effects of dietary supplements of fish oil on the oocyte and early embryo. The study by Zeron et al. (2002) demonstrating greater numbers of high quality oocytes with 
improved membrane integrity on chilling when ewes received diets supplemented with fish oil adds credence to this anticipation of specific benefits. So too does the recent observation by Warzych et al. (2011) of enhanced expression of a marker gene (EEF1A1) for oocyte competence in the oocytes of pigs given a dietary supplement of docosahexaenoic acid.

The first objective of the present study was to measure holistically (endocrine, ovarian and embryo developmental consequences), in superovulated ewes, the effects of two inclusion rates of a dietary supplement of fish oil, vs a zero fish oil 'Control' diet, on ovarian follicular development, ovulation number, embryo numbers, their developmental status at collection (day 5) and during subsequent 48-h in vitro culture. In the absence of unequivocal evidence in the reviewed literature for a direct beneficial effect on the early pre-implantation embryo, a second objective was to examine the discrete effects, during in vitro culture (day 1 to day 7), of sera with contrasting fatty acid profiles including those generated by the two inclusion rates of fish oil, on embryonic development following in vitro fertilization of oocytes aspirated from ovaries retrieved immediately post mortem from ewes at a commercial abattoir.

\section{MATERIAL AND METHODS}

Research procedures in this study were in accordance with the UK's Home Office Animals (Scientific Procedures) Act 1986 and approved by the Animal Experiment Committee of the Scottish Agricultural College.

\section{Experiment 1}

Forty-eight adult Cheviot ewes were allocated randomly in equal numbers to a control diet based on equal parts of oats and sugar beet shreds or the same diet with 3 or $6 \%$ herring oil. The diets were given from $22 \mathrm{~d}$ before egg collection, which occurred $5 \mathrm{~d}$ after intrauterine insemination. All ewes received a $12 \mathrm{~d}$ progestogen sponge ( $0.3 \mathrm{~g}$ Cronolone; Intervet, UK) and $9 \mathrm{mg}$ oFSH (Ovagen, ICP, UK) in 8 equal injections every $12 \mathrm{~h}$ from $60 \mathrm{~h}$ before to $24 \mathrm{~h}$ after sponge removal. Laparoscopic AI using freshly collected ram semen (diluted 1:3 with Dulbecco's phosphate-buffered saline; PBS) was conducted approximately $44 \mathrm{~h}$ after sponge removal. Corpora lutea and large follicles $(>8 \mathrm{~mm}$ diameter) were evaluated at embryo recovery via mid-ventral laparotomy 5 days later. Embryos were cultured in Synthetic Oviduct Fluid medium (SOF; Kuran et al., 2001) with $0.4 \% \mathrm{w} / \mathrm{v} \mathrm{BSA}\left(5 \% \mathrm{CO}_{2}, 5 \% \mathrm{O}_{2} ; 38.5^{\circ} \mathrm{C}\right)$ for up to $48 \mathrm{~h}$; development in vitro was recorded every $24 \mathrm{~h}$. Reflecting the criteria of Lindner and Wright (1983), this 
included stringent evaluation in terms of embryo stage (morula or blastocyst) and morphological status. The latter was based on visual examination as described by Reis et al. (2005), whereby Grade $1=$ excellent, Grade $2=$ good quality, Grade 3 = fair and Grade $4=$ poor quality, with intermediate categories (e.g., Grade 1.5 or 2.25) assigned whenever appropriate. After $48 \mathrm{~h}$ culture, cell numbers (nuclei counts; Hoechst 33342 bisbenzimide fluorochrome) and protein synthesis indices ( ${ }^{3} \mathrm{H}$-phenylalanine incorporation into protein; $\mathrm{cpm}$ ) of individual blastocysts were determined using the methods described by McEvoy et al. (1997) and Kuran et al. (2001). Briefly, labelling of de novo synthesized protein was carried out in separate wells of 16-well dishes, with each well initially containing $15 \mu \mathrm{l}$ of ${ }^{3} \mathrm{H}$-phenylalanine solution comprising, in a 1:9 volume ratio, 10x Dulbecco's modified eagle medium (DMEM; Life Technologies, UK) and aqueous L-[2,6${ }^{3} \mathrm{H}$ ]-phenylalanine $(37 \mathrm{MBq} / \mathrm{ml}$, specific activity $2.1 \mathrm{TBq} / \mathrm{mmol}$; Amersham International, UK). Individual embryos then were added in $100 \mu \mathrm{lOCM}$, giving a total fluid volume of $115 \mu \mathrm{l}$ per well, and incubated for $2 \mathrm{~h}$ at $38.5^{\circ} \mathrm{C}$. At the end of the incubation period, embryos were washed 4 times in ice-cold OCM, and each embryo was stored at $-80^{\circ} \mathrm{C}$ in $50 \mu 1$ of OCM until processing. The processing protocol involved dissolution in $50 \mu \mathrm{l}$ of $0.6 \mathrm{M} \mathrm{NaOH}$, protein precipitation in $30 \mu \mathrm{l}$ of $2.0 \mathrm{M}$ perchloric acid (PCA) and repeated washing with $100 \mu \mathrm{l}$ of $0.2 \mathrm{M}$ PCA, before redissolving the protein in $100 \mu \mathrm{l}$ of $0.3 \mathrm{M} \mathrm{NaOH}$. This, together with $100 \mu \mathrm{l}$ of $0.5 \mathrm{M} \mathrm{HC} 1$ to prevent chemiluminescence, was added to a vial containing $5 \mu \mathrm{l}$ of liquid scintillation counter cocktail (Emulsifier-Safe; Canberra Packard, UK). Scintillations (indicative of radioactivity) were recorded in a beta-counter and, following correction for background radiation readings (gained from concurrent and analogous but embryo-free samples), results were expressed as counts per minute (cpm).

Oestradiol concentrations in plasma collected at AI were determined by radioimmunoassay using the method described by Mann et al. (1995). Dietary effects on the numbers of ovulations (corpora lutea) and of embryos (square-root transformed data), blastocyst development and grade (arcsine-transformed), cell numbers and protein synthesis (log-transformed) and zona-intact diameters were tested by ANOVA.

\section{Experiment 2}

Abattoir-derived ovine oocytes ( 11 batches; $n=80$ per batch) were matured and fertilized in vitro for 22 and $20 \mathrm{~h}$, respectively, using conventional protocols at $38.5^{\circ} \mathrm{C}$ in an atmosphere of $5 \% \mathrm{CO}_{2}$ in air. Briefly, ovaries were collected from a slaughterhouse and transported, at $35^{\circ} \mathrm{C}$, to the laboratory in modified Dulbecco's PBS, containing $50 \mathrm{mg} \mathrm{ml}^{-1}$ kanamycin sulphate. Cumulus-oocyte complexes 
(COCs) were recovered by aspiration from follicles of 2-8 $\mathrm{mm}$ diameter. COCs were then matured in 4-well dishes containing $500 \mu \mathrm{l}$ Maturation Medium; this was Medium 199 with $10 \%$ FCS (v/v) and contained $0.1 \mathrm{mg} / \mathrm{ml} \mathrm{L-glutamine,} 0.1 \mathrm{mg} /$ $\mathrm{ml}$ pyruvate, $10 \mu 1 / \mathrm{ml} \mathrm{LH}$ and $10 \mu 1 / \mathrm{ml} \mathrm{FSH} \mathrm{(Sigma,} \mathrm{UK).} \mathrm{Following} \mathrm{maturation,}$ COCs were washed and the expanded cumulus cells were reduced to approximately 4 layers by pipetting. Spermatozoa from the frozen-thawed ejaculate of one ram were then introduced and co-incubated overnight (day 0 to day 1 ) with the matured oocytes to achieve in vitro fertilization (IVF). Following IVF, presumptive zygotes were washed and then cultured conventionally in $50 \mu \mathrm{l}$ micro-drops, under mineral oil, for seven days $\left(5 \% \mathrm{CO}_{2}, 5 \% \mathrm{O}_{2} ; 38.5^{\circ} \mathrm{C}\right)$ in modified SOF plus one of four contrasting supplementary sera $(10 \% \mathrm{v} / \mathrm{v})$ which were as follows: commercial foetal calf serum (FCS; Sigma, Cat No. F9665) or serum from ewes fed standard rations supplemented with $0 \%$ (Control, C), 3\% (3F) or $6 \%(6 \mathrm{~F}) \mathrm{w} / \mathrm{w}$ fish oil as reported for Experiment 1 and previously by Onal et al. (2000). The 'FCS' treatment was included as a point-of-reference vis-à-vis conventional protocols but, in keeping with the design employed in Experiment 1, embryos exposed to the ' $\mathrm{C}$ ' serum were the designated 'Control' group in this case.

Serum lipid mass was determined gravimetrically and major lipid classes, including triglyceride and phospholipid, were separated by thin layer chromatography on silica gel $\mathrm{G}$ prior to transmethylation of each lipid fraction. Gas-liquid chromatography was used to determine fatty acid composition $(\% \mathrm{w} / \mathrm{w})$, with peaks identified by comparison with standard fatty acid methyl esters. Percentages of presumptive zygotes that, as embryos, had cleaved were recorded (day 3), together with the numbers of blastocysts (day 6+7), their cell numbers (nuclei counts; Hoechst 33342) and zona-inclusive diameters. Morphological criteria, as described for Experiment 1, were again used to assign an appropriate quality grade to each blastocyst. Data representing incidences of embryo cleavage and of blastocyst production from cleaved embryos were analysed using a generalized linear model with binomial distributions (Genstat 5); blastocyst cell numbers and diameters were tested by single-factor ANOVA (Minitab 12) and Chi-square analysis was used to test for treatment effects on the incidence of good quality blastocysts.

\section{RESULTS}

\section{Experiment 1}

Ovulations and embryo yields were unaffected by dietary lipid but oestradiol concentrations increased $(\mathrm{P}<0.05)$, and were associated with a tendency $(\mathrm{P}=0.08)$ 
towards more large follicles at egg collection. Supplementary fish oil tended to suppress the rate of embryo development and extent of blastocyst expansion (diameter; $\mathrm{P}=0.07)$ and did reduce cell number $(\mathrm{P}<0.05)$ but not protein synthesis (Table 1). At the time of embryo collection (day 5) only ewes offered the 'Control' diet yielded blastocysts. Nevertheless, after $48 \mathrm{~h}$ of in vitro culture, the majority of embryos collected from each of the ewe cohorts offered a fish oil-supplemented diet also had reached that stage of development. Further details are summarized in Table 1.

Table 1. Effects of a dietary supplement of fish oil on ovarian response, plasma oestradiol-17 $\beta$ and embryo developmental status at collection (day 5) and following in vitro culture. Data are mean \pm SEM values for 16 ewes per treatment (Experiment 1)

\begin{tabular}{lccc}
\hline Item & $\begin{array}{c}\text { Control } \\
(\mathrm{C})\end{array}$ & $\begin{array}{c}\mathrm{C}+3 \% \text { oil } \\
(3 \mathrm{~F})\end{array}$ & $\begin{array}{c}\mathrm{C}+6 \% \text { oil } \\
(6 \mathrm{~F})\end{array}$ \\
\hline No. of ovulations & $16.9 \pm 1.7$ & $14.9 \pm 1.3$ & $16.1 \pm 1.6$ \\
Embryo yields & $10.25 \pm 1.2$ & $7.69 \pm 1.2$ & $10.33 \pm 1.8$ \\
Follicles $>8 \mathrm{~mm}$ & $0.50 \pm 0.22$ & $1.38 \pm 0.48$ & $1.66 \pm 0.36$ \\
Oestradiol-17, $\mathrm{pg} / \mathrm{ml}$ & $7.04 \pm 0.9^{\mathrm{a}}$ & $12.33 \pm 1.6^{\mathrm{b}}$ & $11.1 \pm 1.7^{\mathrm{ab}}$ \\
Blastocysts collected, \% & $4.8 \pm 2.9$ & 0 & 0 \\
Blastocysts at 24 h, \% & $43 \pm 10.4$ & $32 \pm 9.6$ & $35 \pm 9.5$ \\
Blastocysts at 48 h, \% & $73 \pm 8.7$ & $66 \pm 8.6$ & $67 \pm 9.7$ \\
Grade 1-2 blastocysts at 48 h, \% & $46 \pm 20$ & $38 \pm 23$ & $38 \pm 23$ \\
Blastocyst diameter, $\mu \mathrm{m}$ & $235 \pm 5$ & $218 \pm 7$ & $218 \pm 7$ \\
Blastocyst cell numbers & $124 \pm 12^{\mathrm{a}}$ & $93 \pm 12^{\mathrm{ab}}$ & $83 \pm 13^{\mathrm{b}}$ \\
Protein synthesis index $(\mathrm{cpm})$ & $848 \pm 145$ & $911 \pm 134$ & $1066 \pm 148$ \\
\hline
\end{tabular}

within-rows, values with different superscripts differ: ${ }^{\text {ab }} \mathrm{P}<0.05$

\section{Experiment 2}

Lipid mass in sera from ewes offered dietary lipid $(3 \mathrm{~F}, 6 \mathrm{~F})$ was 2 - to 3 -fold that in foetal calf serum (FCS) (Table 2). Serum source altered relative abundance of triglyceride but not of phospholipid.

Table 2. Lipid mass and major lipid class properties of sera used to supplement $(10 \% \mathrm{v} / \mathrm{v})$ modified SOF (Experiment 2)

\begin{tabular}{lcccc}
\hline Item & $\begin{array}{c}\text { Foetal calf } \\
\text { serum }\end{array}$ & $\begin{array}{c}\text { Control } \\
(\mathrm{C})\end{array}$ & $\begin{array}{c}\mathrm{C}+3 \% \text { oil } \\
(3 \mathrm{~F})\end{array}$ & $\begin{array}{c}\mathrm{C}+6 \% \text { oil } \\
(6 \mathrm{~F})\end{array}$ \\
\hline Lipid mass; mg per 100 g serum & 110 & 180 & 240 & 300 \\
Triglyceride; \% total lipid (w/w) & 4 & 13 & 10 & 8 \\
Phospholipid; \% total lipid (w/w) & 38 & 37 & 39 & 42 \\
\hline
\end{tabular}

Palmitic, stearic, oleic and linoleic acids were the most abundant fatty acids in all 4 sera. $\mathrm{C}$ and 3F sera both had marginally lower PUFA levels in triglyceride (13 to $16 \% \mathrm{w} / \mathrm{w}$ ) than either 6F or FCS (19 to $20 \%$ ). Polyunsaturated fatty acids therefore consistently accounted for less than $25 \%(\mathrm{w} / \mathrm{w})$ of total fatty acids in serum triglycerides. 
Zygote cleavage and blastocyst yield data were not affected significantly by serum source (Table 3$)$. Mean $( \pm$ SEM) cell numbers and diameters were highest among blastocysts produced in the presence of $\mathrm{C}$ and $3 \mathrm{~F}$ sera. FCS-derived blastocysts had lowest cell numbers $(\mathrm{P}<0.001)$ and least expansion $(\mathrm{P}<0.005)$.

Table 3. In vitro embryo production (mean $\pm \mathrm{SEM})$ data (Experiment 2$)$

\begin{tabular}{lcccc}
\hline Item & $\begin{array}{c}\text { Foetal calf } \\
\text { serum }\end{array}$ & $\begin{array}{c}\text { Control } \\
(\mathrm{C})\end{array}$ & $\begin{array}{c}\mathrm{C}+3 \% \text { oil } \\
(3 \mathrm{~F})\end{array}$ & $\begin{array}{c}\mathrm{C}+6 \% \text { oil } \\
(6 \mathrm{~F})\end{array}$ \\
\hline Day 3 cleaved zygotes; \% of cultured & $96 \pm 1.6$ & $97 \pm 1.5$ & $97 \pm 1.0$ & $99 \pm 0.9$ \\
Day 6+7 blastocysts; \% of cleaved & $26 \pm 5.2$ & $28 \pm 5.2$ & $34 \pm 5.5$ & $31 \pm 3.2$ \\
Day 6+7 blastocysts; Grade 1-2/total & $20 / 50$ & $34 / 55$ & $37 / 68$ & $31 / 64$ \\
Day 6+7 blastocysts; Grade 1-1.5/total & $5 / 50^{\mathrm{c}}$ & $15 / 55$ & $22 / 68^{\mathrm{a}}$ & $10 / 64^{\mathrm{b}}$ \\
Blastocyst diameter, $\mu \mathrm{m}(\mathrm{n}=56$ to 73) & $182 \pm 2^{\mathrm{a}}$ & $194 \pm 3^{\mathrm{c}}$ & $194 \pm 3^{\mathrm{c}}$ & $190 \pm 2^{\mathrm{c}}$ \\
Total cell counts $(\mathrm{n}=43$ to 62) & $50 \pm 3^{\mathrm{d}}$ & $60 \pm 3^{\mathrm{e}}$ & $60 \pm 2^{\mathrm{e}}$ & $55 \pm 2^{\mathrm{e}}$ \\
\hline
\end{tabular}

within rows, paired superscripts differ as follows: ${ }^{\text {ab }} \mathrm{P}<0.05 ;{ }^{\text {acc }} \mathrm{P}<0.005$; ${ }^{\text {de }} \mathrm{P}<0.001$

While overall incidence of Grade 1-2 blastocysts did not differ among treatments, there was a difference in the incidence of very good quality embryos. Proportionately more Grade 1-1.5 blastocysts were produced in the presence of $3 \mathrm{~F}$ serum than in media with either $6 \mathrm{~F}$ serum $(\mathrm{P}<0.05)$ or FCS $(\mathrm{P}<0.005)$, implying an intermediate preference for lipid provision in the embryo's environment (Table 3).

\section{DISCUSSION}

The results of the study did not give evidence for a stimulatory effect of the fish oil supplement on the superovulatory response of the ewes, on embryo yields or on embryo quality. Indeed, on the basis of their slower development both in vivo and in vitro, embryos from the fish oil supplemented ewes bore similarities to those seen when superovulated ewes are exposed to high feeding levels (McEvoy et al., 1995; Lozano et al., 2003). In that scenario it was argued that the causal mechanism was the reduction in plasma progesterone concentrations that accompanies high levels of feeding in the ewe (McEvoy et al., 1995). Although progesterone concentrations were not measured in the present study it is unlikely that the fish oil would have reduced them since all the evidence, albeit mostly from dairy cattle studies (Staples and Thatcher, 2005; Bilby et al., 2006; Petit and Twagiramungu, 2006; Thangavelu et al., 2007) but also supported by sheep data (Kuran et al., 1999), indicates that supplementary dietary lipids elevate progesterone. In the Kuran et al. (1999) study referred to just now, we found that dietary lipid was associated with significantly enhanced progesterone synthesis in primary explants of ovine luteal tissue in vitro. However, because fish oil was not 
the dietary lipid supplement in that instance, the recent reports by Wonnacott et al. (2010) and Hughes et al. (2011) are more pertinent to the current study. Among their findings, Hughes et al. (2011) indicated that n-3 PUFAs specifically enhance progesterone synthesis by thecal cells of ovine follicles and that this is associated with increased StAR transcript expression, notable because the translated steroidogenic acute regulatory protein is an important facilitator of cholesterol transport to mitochondrial membranes, the rate-limiting step in progesterone biosynthesis (Stocco and Clark, 1996; Niswender, 2002). Further reassurance that fish oil was unlikely to have compromised luteal-phase progesterone production in the present study derives from the fact that n-3 fatty acids in fish oil appear able to confer an additional benefit of reducing the synthesis of the uterine antiluteolytic agent, $\mathrm{PGF}_{2 a}$, even when luteal-phase progesterone concentrations are low (Wamsley et al., 2005). In the present study care was taken to ensure that progesterone concentrations during oocyte maturation were adequate to foster optimum oocyte quality by replacing the progestogen sponge on day 7 of the 12-day progestogen priming phase and, with no evidence for premature luteal regression (corpora lutea were inspected directly during laparotomy), the superovulatory response ensured that early embryo development in vivo was not compromised by low post-ovulatory progesterone concentrations.

In contrast to their stimulatory effect on plasma progesterone, dietary lipids are generally considered to suppress plasma oestradiol concentrations, although the observations on which this conclusion is based are mostly from dairy cow studies (Staples et al., 1998). In oestrous-cyclic ewes, Kuran et al. (1999) found that supplementing their diet with a calcium soap of palm oil (predominantly palmitate; C16:0) had no significant effect on plasma oestradiol. However, Lammoglia et al. (1997) reported that enrichment of the diet of oestrous-cyclic Brahman cows with oleic (C18:1) and linoleic (C18:2n-6) acids by the inclusion of rice bran increased plasma oestradiol concentrations. In dairy cows given a diet supplemented with linseed oil which is rich in linolenic acid (C18:3n-3), Robinson et al. (2002a) observed higher follicular-phase plasma oestradiol concentrations than in unsupplemented controls, with those given soyabean oil (rich in linoleic acid) having intermediate values. These findings, when taken in conjunction with the data from the present study, imply that the stimulatory effect of dietary lipid supplements on plasma oestradiol may be fatty acid-specific. The effect does not, however, appear to be linear in that in the present study, compared to the 'Control' diet-mediated outcome, the increases in oestradiol were similar for the 3 and $6 \%$ levels of fish oil supplementation (Table 1); thus plateau oestradiol concentrations may occur at under the $3 \%$ level of fish oil inclusion. Care is needed, however, in interpreting data from different studies because, as recently noted by Zachut et al. (2010) when discussing their oestradiol results vis-à-vis those of Robinson 
et al. (2002a), time of sampling must be taken into account as it has a profound influence on outcomes and inferred effects.

Common ovarian features of lipid supplementation in dairy cows are increases in follicle number (Thatcher et al., 2006) and in the diameter of the dominant follicle (Staples and Thatcher, 2005) with the increases appearing to be most pronounced in association with long-chain polyunsaturated fatty acids such as eicosapentaenoic (EPA) and docosahexaenoic (DHA), of which fish oil is a rich source. The tendency, in the present study, for ewes given the fish oil supplement to have more large follicles at embryo collection on day 5 , relative to their 'Control' ewe counterparts $(\mathrm{P}=0.08)$, was in keeping with those observations but notably did not reflect a compromised capacity to ovulate (Table 1). The nonlinear nature of the ovarian response in terms of numbers of large follicles visvis level of fish oil supplementation is similar to the oestradiol response, implying that maximum stimulation of follicular growth occurred around the 3\% level of fish oil inclusion. Whether the increased oestradiol is a consequence of, or the reason for, the stimulatory effect of the fish oil on the number of large follicles is unknown. Although smaller and less oestrogenic dominant follicles are associated with poor fertility in high-yielding dairy cows (Lucy, 2003), over-stimulation of circulating oestrogen concentrations soon after ovulation, as in the present study, could be detrimental to embryo development and survival through the enhancing effect of oestradiol on uterine prostaglandin secretion (Staples et al., 1998).

In terms of the rate of embryo development in vivo, there was clear evidence that, relative to the influence of the 'Control' diet, fish oil supplementation compromised it and, with the exception of their enhanced metabolism in the form of increased protein synthesis, other indices of embryo development such as cell number and diameter of blastocysts were also compromised by the feeding of fish oil. Intuitively, these effects on the embryo would seem undesirable in that delayed development coupled with up-regulation of metabolism is not considered to be conducive to good preimplantation embryo survival (Leese, 2002) and may be indicative of a 'stress' response (Leese et al., 2008). Yet, on the basis of their ability to alter the expression of the uterine IGF system in a way that is conducive to good embryo survival, the PUFAs of fish oil are regarded as having the potential for improving the reproductive performance of the high-yielding dairy cow (Coyne et al., 2011). This dichotomy, whereby potentially beneficial lipid-derived stimuli for endocrine functions or prostaglandin attenuation are co-incident with a capacity for direct and detrimental effects on oocyte/embryo competence (Kuran et al., 1999; McEvoy et al., 2000a; Robinson et al., 2002b; Leroy et al., 2008; Sturmey et al., 2009), reinforces the argument that both careful dietary management and further study of various lipid-linked effects in vivo and in vitro are warranted. In cattle and sheep oocytes, polyunsaturated fatty acids constitute 
only a minor proportion of acyl-containing lipids; and among them both EPA and DHA are found in modest amounts, together comprising less than $5 \%(\mathrm{w} / \mathrm{w})$ of total fatty acids in oocyte lipid (McEvoy et al., 2000b); these are nevertheless two developmentally-significant long-chain PUFAs, of which fish oil is a rich source. The crux in making long-chain PUFAs readily available in the oocyte/embryo environment is that both their suitability and their adequate fortification against risks of oxidation are major determinants of ultimate effects. Simply stated, care in fish oil provision is needed lest on the one hand the would-be beneficial fatty acids serve as a focus for unwanted and excessive peroxidative damage or on the other hand oocytes and embryos 'absorb' too much of something they naturally tend to restrict to low levels. EPA and DHA are marginal and vulnerable constituents of oocytes and embryos so their presence requires provision of (preferably fat-soluble) antioxidants and accordingly the diets used in the present study were fortified with vitamin E (alpha-tocopherol). Arguably, although sometimes overlooked, much of the perceived benefit of EPA- and DHA-rich supplements in various situations could be due to more wide-ranging benefits of concurrent antioxidant provision per se, something which should not be ignored because alteration of antioxidant status can have profound effects, not only in the context of reproduction (Breque et al., 2006; Ruder et al., 2008; Rooke et al., 2008, 2012) but even in quite debilitating circumstances (Vijayaraghavan et al., 2005; Zablocka and Janusz, 2008). In the present study control diets were fortified with vitamin $\mathrm{E}$ to the same extent as the fish oil-enriched diets and, consequently, effects of the latter were unlikely to have been merely a reflection of enhanced antioxidant status.

Until recently, there was little or no evidence, from studies of ruminant species, that dietary fatty acids significantly influenced in vivo the fatty acid composition of oocytes per se. Indeed Adamiak et al. (2006) suggested there was possible follicular-level modulation of saturated:polyunsaturated fatty acid balance, achieved via selective uptake, to guard against excessive PUFA accumulation in the oocyte's immediate environment in vivo. However, Wonnacott et al. (2010) did report differences in terms of the fatty acid composition of denuded oocytes from ewes fed diets enriched with either n-3 or n-6 PUFAs, the differences being achieved by provision of linseed oil $(10 \mathrm{~g} / \mathrm{kg})$ plus salmon oil $(35 \mathrm{~g} / \mathrm{kg})$ in the $\mathrm{n}-3$ ration and sunflower oil $(45 \mathrm{~g} / \mathrm{kg})$ in the $\mathrm{n}-6$ ration; compared with the current study, this equated to $4.5 \%$ oil inclusion in each ration. While the $n-6 / n-3$ PUFA ratio of oocytes differed significantly between diets in the study of Wonnacott et al. (2010), total PUFAs consistently comprised only $13 \%$ of the total fatty acid complement of the oocytes in each case, a value consistent with earlier evidence that these are much less abundant than saturated fatty acids in ruminant oocytes (McEvoy et al., 2000b). Notably, the n-6/n-3 PUFA ratio of 0.7 recorded by Wonnacott et al. (2010) for oocytes from ewes given the diet with salmon oil is 
much closer to the 1.1 ratio we recorded previously for sheep oocytes (McEvoy et al., 2000b) than the dramatically different ratio of 8.3 associated with their sunflower oil-enriched ' $n-6$ ' diet. Consequently, although the dietary inclusion of fish oil in the present study may have influenced oocyte/embryo composition in vivo, the effects were unlikely to have dramatically altered either their PUFA complement or n-6/n-3 ratios across treatments. Nevertheless, we cannot exclude the possibility that the inhibitory effect of supplementary fish oil on the rate of development of embryos in vivo (blastocysts were found at collection only among embryos from ewes offered the control diet; Table 1) was the result of an alteration in their polyunsaturated fatty acid composition.

Whether it was some effect on the oocytes of fish oil inclusion in the diet that influenced early embryo development in the in vivo study, or it was a solely postfertilization phenomenon cannot be ascertained from the in vitro embryo production study. Fatty acid inclusion in embryo culture systems is not new (Kane, 1979) but much remains to be discovered about these compounds which as well as being sources of energy (Sturmey et al., 2009) have, along with their derivatives, numerous biological roles mediated on the basis of both structure and function, most critically perhaps via their influences on membrane composition, fluidity and resilience. Here the addition to the embryo culture medium of serum harvested from ewes receiving the fish oil supplements at the 3\% dietary inclusion rate had no adverse effects on the number and diameter of day 6 and 7 blastocysts compared with serum from control ewes and indeed slightly improved the proportion of blastocysts of very good quality (Grades 1 to 1.5). Compared with foetal calf serum, which despite its limitations (McEvoy et al., 2000a), has been widely used as a supplement to in vitro embryo culture media, the inclusion of serum from ewes fed $3 \%$ fish oil resulted in significant increases in the number and diameter of very good quality (Grade 1-1.5) blastocysts as well as their total cell counts. In contrast, in vitro inclusion of serum from ewes that received the $6 \%$ fish oil diet was associated with an approximate halving of the number of very good quality blastocysts but there was no evidence for the associated reduction in embryo diameter seen in the in vivo experiment and only a small, but non-significant, reduction in cell number was recorded. Nonetheless the data do suggest that an intermediate inclusion rate of long-chain PUFAs from fish oil (EPA and DHA) in culture media may be preferable for maximizing the number and quality of blastocysts. It is highly likely therefore, that despite their requirements as essential constituents of mammalian oocytes, high levels of EPA and DHA could compromise the processes of oocyte maturation and embryo development. This reflects their vulnerability and capacity to be a focus for oxidative damage (Reis, 2003).

As an indicator of the extent to which long-chain PUFAs can be difficult for mammalian cells to cope with, it is notable that fatty acids and their metabolites 
can be regulators of apoptosis (Rudolph et al., 2001) and, more specifically, EPA without antioxidant supplement has been used to induce apoptosis in cancer cells, the apoptosis considered to be triggered in part by inevitable lipid peroxidation due to the presence of so many carbon-carbon double bonds (Li et al., 2006). In the same vein, Puskas et al. (2010) demonstrated that EPA and DHA but not monounsaturated oleic acid synergised effectively with lipid-binding thalidomide analogues to induce oxidative stress in cancer cells. Albeit that such strategies aim to expose cancer cells to lethal antitumorigenic consequences, they also underline the capacity of PUFAs to exert dramatically different influences in accordance with the extent to which they are either protected from or are a focus for oxidative damage. Clearly, to avoid the latter, beneficial addition of EPA and DHA to embryo culture media therefore would require careful provision of antioxidative protection, something which even in more conventional circumstances probably is sub-optimal, given the beneficial developmental effects accruing from vitamin $\mathrm{E}$ (or vitamin $\mathrm{E}$ analogue) provision during in vitro culture of preimplantation ruminant embryos (Olson and Seidel, 2000; Reis et al., 2003; Natarajan et al., 2010; Rooke et al., 2012). The principle of damage avoidance is consistent with the 'Quiet Embryo' hypothesis (Leese, 2002; Leese et al., 2008) and matches the aim of embryologists to promote both embryo survival and blastomere proliferation rather than avoidable damage and consequent apoptosis (although, operating properly, apoptosis is of course a crucial self-regulatory process). Although in the present study, there was apparently adequate diet-related antioxidant fortification of the 'Control' serum but perhaps more marginal protection of the fish oilenriched sera used in vitro, these antioxidant-enrichment scenarios are not typical of more conventional in vitro embryo production. The fact, for example, that FCS did not emulate the 'Control' serum in terms of the calibre of embryos produced in vitro in the current study may reflect an inferior antioxidant status but this was not tested. There is, nevertheless, a need for ongoing investigations towards identification of compounds capable of enhancing antioxidant function and status during in vitro embryo culture. Among the most recent reports, Lee et al. (2011) have identified 3,4-dihydroxyflavone as an agent having both antioxidative and antiapoptotic properties of benefit to bovine embryos in vitro.

Ultimately, for each of the production system scenarios (in vivo and in vitro) studied in the present investigation, fuller understanding of both fatty acid roles and the antioxidant requirements to safeguard them will be prerequisites to optimizing yields of developmentally competent and functionally normal embryos. On the basis of the multi-faceted influences of long-chain PUFAs on membrane properties and membrane-linked processes, considerable additional research is required for optimal concentrations (or more pragmatically, biologically beneficial ranges) to be deduced. Such information could complement and facilitate insights into the 
roles of endogenous lipids (Sturmey et al., 2009) as well as highlighting their inter-connectedness; a case in point is recent evidence that, in the case of EPA and DHA, these two long-chain PUFAs could have beneficial effects in so far as they regulate the expression of the desaturases (Al Darwich et al., 2010) and potentially therefore the nature of the fatty acid-derived energy supply.

\section{CONCLUSIONS}

Dietary fish oil supplementation had no effect on the superovulatory response of ewes or their embryo numbers. It increased both the number of large $(>8 \mathrm{~mm})$ ovarian follicles and plasma oestradiol concentrations at embryo recovery on day 5 , the effects being similar for both the 3 and $6 \%$ fish oil inclusion rates. Compared with an unsupplemented control diet, both inclusion rates were accompanied by a similar slower rate of embryo development and associated limitations in blastocyst diameter and cell number. In contrast protein metabolism was enhanced by dietary lipid supplementation. For in vitro-produced embryos, cleavage rates, blastocyst diameters and cell numbers were similar using media supplemented with either foetal calf serum or serum harvested from ewes receiving 0 ('Control'), 3 or $6 \%$ fish oil. The proportion of Grade 1-1.5 blastocysts was marginally improved in the presence of 3\% fish oil compared with no fish oil ('Controls'), whereas for $6 \%$ fish oil the incidence was halved. Notably, these parameters were significantly better than corresponding results for foetal calf serum, indicating that conventional supplements are sub-optimal. Direct and potentially detrimental effects of excessive fish oil inclusion were suggested in data for the $6 \%$ fish oil treatment, with incidence of very good quality blastocysts reduced relative to 'Controls'. The nature of the effects of dietary fish oil supplementation suggests that at lower levels than those used in the present study, there may be benefits for both in vivo and in vitro embryo production but, in all instances, antioxidant status will be a crucial determinant of the consequences of fatty acid and lipid or lipoprotein provision.

\section{ACKNOWLEDGEMENTS}

The authors thank M.E. Staines, G.J. McCallum and M. Ewen for skilled technical assistance. 


\section{REFERENCES}

Adamiak S.J., Mackie K., Watt R.G., Webb R., Sinclair K.D., 2005. Impact of nutrition on oocyte quality: cumulative effects of body composition and diet leading to hyperinsulinemia in cattle. Biol. Reprod. 73, 918-926

Adamiak S.J., Powell K., Rooke J.A., Webb R., Sinclair K.D., 2006. Body composition, dietary carbohydrates and fatty acids determine post-fertilization development of bovine oocytes in vitro. Reproduction 131, 247-258

Al Darwich A., Perreau C., Petit M.H., Papillier P., Dupont J., Guillaume D., Mermillod P., Guignot F., 2010. Effect of PUFA on embryo cryoresistance, gene expression and AMPK $\alpha$ phosphorylation in IVF- derived bovine embryos. Prostag. Oth. Lipid M. 93, 30-36

Bilby T.R., Block J., do Amaral B.C., Sa Filho O., Silvestre F.T., Hansen P.J., Staples C.R., Thatcher W.W., 2006. Effects of dietary unsaturated fatty acids on oocyte quality and follicular development in lactating dairy cows in summer. J. Dairy Sci. 89, 3891-3903

Bilby T.R., Block J., Sa Filho O., Silvestre F.T., Hansen P.J., Staples C.R., Thatcher W.W., 2005. Effects of unsaturated fatty acids on oocyte quality and follicular development in lactating dairy cows in summer. Biol. Reprod. S1, 140-141

Breque C., Surai P., Brillard J.P., 2006. Antioxidant status of the lower oviduct in the chicken varies with age and dietary vitamin E supplementation. Mol. Reprod. Dev. 73, 1045-1051

Cancino-Arroyo G., Ake-Lopez R., Herrera J., Centurion F., Ordonez-Leon A., 2006. Effect of dietary fat supplementation on oocyte and embryo quality and on early embryonic development of sheep. Reprod. Fert. Develop. 18, 224

Cerri R.L.A., Bruno R.G.S., Chebel R.C., Galvao K.N., Rutigliano H., Juchem S.O., Thatcher W.W., Luchini D., Santos J.E.P., 2004. Effect of fat sources differing in fatty acid profile on fertilization rate and embryo quality in lactating dairy cows. J. Anim. Sci. 82, Suppl. 1, 297 (Abstr.)

Cerri R.L.A., Juchem S.O., Chebel R.C., Rutigliano H.M., Bruno R.G.S., Galvao K.N., Thatcher W.W., Santos J.E.P., 2009. Effect of fat source differing in fatty acid profile on metabolic parameters, fertilization, and embryo quality in high-producing dairy cows. J. Dairy Sci. 92, $1520-1531$

Coyne G.S., Kenny D.A., Waters S.M., 2011. Effect of dietary n-3 polyunsaturated fatty acid supplementation on bovine uterine endometrial and hepatic gene expression of the insulin-like growth factor system. Theriogenology 75, 500-512

Fouladi-Nashta A.A., Gutierrez C.G., Gong J.G., Garnsworthy P.C., Webb R., 2007. Impact of dietary fatty acids on oocyte quality and development in lactating dairy cows. Biol. Reprod. 77, 9-17

Fouladi-Nashta A.A., Gutierrez C.G., Russell H.F., Garnsworthy P.C., Webb R., 2004. Effects of dietary fatty acids on oocyte quality and development in lactating dairy cows. Biol. Reprod., Special Issue, S1, p. 107, Abstr. 62

Hughes J., Kwong W.Y., Li D., Salter A.M., Lea R.G., Sinclair K.D., 2011. Effects of omega-3 and -6 polyunsaturated fatty acids on ovine follicular cell steroidogenesis, embryo development and molecular markers of fatty acid metabolism. Reproduction 141, 105-118

Jorritsma R., Cesar M.L., Hermans J.T., Krutwagen C.L.J.J., Vos P.L.A.M., Kruip T.A.M., 2004. Effects of non-esterified fatty acids on bovine granulosa cells and development potential of oocytes in vitro. Anim. Reprod. Sci. 81, 225-235

Juchem S.O., Cerri R.L.A., Bruno R. et al., 2004. Effect of feeding Ca salts of palm oil (PO) or a blend of linoleic and monoenoic trans fatty acids (LTFA) on uterine involution and reproductive performance in Holstein cows. J. Anim. Sci. 82, Suppl. 1, 310 (Abstr.)

Juchem S.O., Cerri R.L.A., Villasenor M. et al., 2010. Supplementation with calcium salts of linoleic and trans-octadecanoic acids improves fertility of lactating dairy cows. Reprod. Domest. Anim. $45,55-62$ 
Kane M.T., 1979. Fatty acids as energy sources for culture of one-cell rabbit ova to viable morulae. Biol. Reprod. 20, 323-332

Kruip T.A.M., Wensing T., Vos P.L.A.M., 2001. Characteristics of abnormal puerperium in dairy cattle and the rationale for common treatments. In: M.G. Diskin (Editor). Fertility in the High Producing Dairy Cow. Occasional Publication No. 26. Brit. Soc. Anim. Sci. Edinburgh, pp. 63-79

Kuran M., Onal A., Robinson J.J., Mackie K., Speake B.K., McEvoy T.G., 1999. A dietary supplement of calcium soaps of fatty acids enhances luteal function in sheep. Anim. Sci. 69, 385-393

Kuran M., Robinson J.J., Staines M.E., McEvoy T.G., 2001. Development and de novo protein synthetic activity of bovine embryos produced in vitro in different culture systems. Theriogenology 55, 593-606

Lammoglia M.A., Willard S.T., Hallford D.M., Randel R.D., 1997. Effects of dietary fat on follicular development and circulating concentrations of lipids, insulin, progesterone, estradiol-17 $\beta, 13$, 14-dihydro-15-keto-prostaglandin F2 $\alpha$ and growth hormone in oestrous cyclic Brahman cows. J. Anim. Sci. 75, 1591-1600

Lapa M., Marques C., Alves S., Vasques M., Baptista M., Carvalhais I., Silva Pereira M., Horta A., Bessa R., Pereira R., 2011. Effects of trans-10 cis-12 conjugated linoleic acid on bovine oocyte competence and fatty acid composition. Reprod. Domest. Anim. 46, 904-910

Lee K.S., Kim E.Y., Jeon K. et al., 2011.3,4-Dihydroxyflavone acts as an antioxidant and antiapoptotic agent to support bovine embryo development in vitro. J. Reprod. Dev. 57, 127-134

Leese H.J., 2002. Quiet please, do not disturb: a hypothesis of embryo metabolism and viability. Bioessays 24, 845-849

Leese H.J., Baumann C.G., Brison D.R., McEvoy T.G., Sturmey R.G., 2008. Metabolism of the viable mammalian embryo: quietness revisited. Mol. Hum. Reprod. 14, 667-672

Leroy J.L.M.R., Van Soom A., Opsomer G., Goovaerts I.G., Bols P.E., 2008. Reduced fertility in high-yielding dairy cows: are the oocyte and embryo in danger? Part II. Mechanisms linking nutrition and reduced oocyte and embryo quality in high yielding dairy cows. Reprod. Domest. Anim. 43, 623-632

Leroy J.L.M.R., Vanholder T., Mateusen B., Christophe A., Opsomer G., de Kruif A., Genicot G., Van Soom A., 2005. Non-esterified fatty acids in follicular fluid of dairy cows and their effect on developmental capacity of bovine oocytes in vitro. Reproduction 130, 485-495

Li M., Kong Z.M., Liu Z.L., 2006. Antioxidant enzyme activities and lipid peroxidation induced by eicosapentaenoic acid (EPA) in PC12 cells. Cell Biol. Toxicol. 22, 331-337

Lindner G.M., Wright Jr. R.W., 1983. Bovine embryo morphology and evaluation. Theriogenology 20, 407-416

Lozano J.M., Lonergan P., Boland M.P., O'Callaghan D., 2003. Influence of nutrition on the effectiveness of superovulation programmes in ewes: effect on oocyte quality and postfertilization development. Reproduction 125, 543-553

Lucy M.C., 2003. Mechanisms linking nutrition and reproduction in postpartum cows. In: B.K. Campbell, R. Webb, H. Dobson, C. Doberska (Editors). Reproduction in Domestic Ruminants V. Society for Reproduction and Fertility, UK. Reproduction, Suppl. 61, 415-427

Mann G.E., Lamming G.E., Fray M.D., 1995. Plasma oestradiol and progesterone during early pregnancy in the cow and the effects of treatment with buserelin. Anim. Reprod. Sci. 37, 121131

Marei W.F., Wathes D.C., Fouladi- Nashta, A.A., 2009. The effect of linolenic acid on bovine oocyte maturation and development. Biol. Reprod. 81, 1064-1072

Marei W.F., Wathes D.C., Fouladi-Nashta A.A., 2010. Impact of linoleic acid on bovine oocyte maturation and embryo development. Reproduction 139, 979-988 
McEvoy T.G., Coull G.D., Broadbent P.J., Hutchinson J.S.M., Speake B.K., 2000b. Fatty acid composition of lipids in immature cattle, pig and sheep oocytes with intact zona pellucida. J. Reprod. Fertil. 118, 163-170

McEvoy T.G., Robinson J.J., Aitken R.P., Findlay P.A., Palmer R.M., Robertson I.S., 1995. Dietaryinduced suppression of pre-ovulatory progesterone concentrations in superovulated ewes impairs the subsequent in vivo and in vitro development of their ova. Anim. Reprod. Sci. 39, 89-107

McEvoy T.G., Robinson J.J., Aitken R.P., Findlay P.A., Robertson I.S., 1997. Dietary excesses of urea influence the viability and metabolism of preimplantation sheep embryos and may affect fetal growth among survivors. Anim. Reprod. Sci. 47, 71-90

McEvoy T.G., Sinclair K.D., Young L.E., Wilmut I., Robinson J.J., 2000a. Large offspring syndrome and other consequences of ruminant embryo culture in vitro: relevance to blastocyst culture in human ART. Hum. Fert. 3, 238-246

Natarajan R., Shankar M.B., Munuswamy D., 2010. Effect of alpha-tocopherol on in vitro maturation of sheep oocytes and in vitro development of preimplantation sheep embryos to the blastocyst stage. J. Assist. Reprod. Genet. 27, 483-490

Niswender G.D., 2002. Molecular control of luteal secretion of progesterone. Reproduction 123, 333-339

Olson, S., Seidel, G.E., 2000. Culture of in vitro-produced bovine embryos with vitamin E improves development in vitro and after transfer to recipients. Biol. Reprod. 62, 248-252

Onal A.G., Robinson J.J., Kuran M., King M.E., Staines M.E., Hutchinson J.S.M., McEvoy T.G., 2000. Effects of dietary supplementation of fish oil on the yield, quality and in vitro maturation of embryos from superovulated sheep. Theriogenology 53, 281

Pereira R.M., Carvalhais I., Pimenta J. et al., 2008. Biopsied and vitrified bovine embryos viability is improved by trans 10 , cis 12 conjugated linoleic acid supplementation during in vitro embryo culture. Anim. Reprod. Sci. 106, 322-332

Petit H.V., Twagiramungu H., 2006. Conception rate and reproductive function of dairy cows fed different fat sources. Theriogenology 66, 1316-1324

Puskas L.G., Feher L.Z., Vizler C. et al., 2010. Polyunsaturated fatty acids synergize with lipid droplet binding thalidomide analogs to induce oxidative stress in cancer cells. Lipids Health Dis. 9, 56 (9 pp.)

Reis A., 2003. Effects of lipids and fatty acids on preimplantation development and viability of ruminant embryos. Ph.D. Thesis. The University of Aberdeen (Scotland)

Reis A., McCallum G.J., McEvoy T.G., 2005. Accumulation and distribution of neutral lipid droplets is non-uniform in ovine blastocysts produced in vitro in either the presence or absence of serum. Reprod. Fert. Develop. 17, 815-823

Reis A., Rooke J.A., McCallum G.J., Staines M.E., Lomax M.A., McEvoy T.G., 2003. Consequences of exposure to serum, with or without vitamin E supplementation, in terms of the fatty acid content and viability of bovine blastocysts produced in vitro. Reprod. Fert. Develop. 15, 275284

Robinson J.J., Ashworth C.J., Rooke J.A., Mitchell L.M., McEvoyT.G., 2006. Nutrition and fertility in ruminant livestock. Anim. Feed Sci. Tech. 126, 259-276

Robinson J.J., Rooke J.A., McEvoy T.G., 2002b. Nutrition for conception and pregnancy. In: M. Freer, H. Dove (Editors). Sheep Nutrition. CABI Publishing (UK), pp. 189-211

Robinson R.S., Pushpakumara P.G.A., Cheng Z., Peters A.R., Abayasekara D.E.E., Wathes D.C., 2002a. Effects of dietary polyunsaturated fatty acids on ovarian and uterine function in lactating dairy cows. Reproduction 124, 119-131

Rooke J.A., Dwyer C.M., Ashworth C.J., 2008. The potential for improving physiological, behavioural and immunological responses in the neonatal lamb by trace element and vitamin supplementation of the ewe. Animal 2, 514-524 
Rooke J.A., Watt R.G., Ashworth C.J., McEvoy T.G., 2012. Inclusion of bovine lipoproteins and the vitamin $\mathrm{E}$ analogue, Trolox, during in vitro culture of bovine embryos changes both embryo and fetal development. Reprod. Fert. Develop. 24, 309-316

Ruder E.H., Hartman T.J., Blumberg J., Goldman M.B., 2008. Oxidative stress and antioxidants: exposure and impact on female fertility. Hum. Reprod. Update 14, 345-357

Rudolph I.L., Kelley D.S., Klasing K.C., Erickson K.L., 2001. Regulation of cellular differentiation and apoptosis by fatty acids and their metabolites. Nutr. Res. 21, 381-393

Staples C.R., Burke J.M., Thatcher W.W., 1998. Influence of supplemental fats on reproductive tissues and performance of lactating cows. J. Dairy Sci. 81, 856-871

Staples C.R., Thatcher W.W., 2005. Effects of fatty acids on reproduction of dairy cows. In: P.C. Garnsworthy, J. Wiseman (Editors). Recent Advances in Animal Nutrition. Nottingham University Press, Nottingham, pp. 229-256

Stocco D. M., Clark B.J., 1996. Role of steroidogenic acute regulatory protein (StAR) in steroidogenesis. Biochem. Pharmacol. 51, 197-205

Sturmey R.G., Reis A., Leese H.J., McEvoy T.G., 2009. Role of fatty acids in energy provision during oocyte maturation and early development. Reprod. Domest. Anim. 44, Suppl. 3, 50-58

Thangavelu G., Colazo M.G., Ambrose D.J., Oba M., Okine E.K., Dyck M.K., 2007. Diets enriched in unsaturated fatty acids enhance early embryonic development in lactating Holstein cows. Theriogenology 68, 949-957

Thatcher W.W., Bilby T.R., Bartolome J.A., Silvestre F., Staples C.R., Santos J.E.P., 2006. Strategies for improving fertility in the modern dairy cow. Theriogenology 65, 30-44

Vijayaraghavan R., Suribabu C.S., Sekar B., Oommen P.K., Kavithalakshmi S.N., Madhusudhanan N., Panneerselvam C., 2005. Protective role of vitamin E on the oxidative stress in Hansen's disease (leprosy) patients. Eur. J. Clin. Nutr. 59, 1121-1128

Wamsley N.E., Burns P.D., Engle T.E., Enns R.M., 2005. Fish meal supplementation alters uterine prostaglandin F2 $\alpha$ synthesis in beef heifers with low luteal-phase progesterone. J. Anim. Sci. $83,1832-1838$

Warzych E., Cieslak A., Pawlak P., Renska N., Pers-Kamczyc D., Lechniak D., 2011. Maternal nutrition affects the composition of follicular fluid and transcript content in gilt oocytes. Vet. Med.-Czech. 56, 156-167

Wonnacott K.E., Kwong W.Y., Hughes J., Salter A.M., Lea R.G., Garnsworthy P.C., Sinclair K.D., 2010. Dietary omega-3 and -6 polyunsaturated fatty acids affect the composition and development of sheep granulosa cells, oocytes and embryos. Reproduction 139, 57-69

Yaakub H., O'Callaghan D., Boland M.P., 1999. Effect of type and quantity of concentrates on superovulation and embryo yield in beef heifers. Theriogenology 51, 1259-1266

Zablocka A., Janusz M., 2008. The two faces of reactive oxygen species. Post. Hig. Med. Dosw. 62, 118-124

Zachut M., Dekel I., Lehrer H., Arieli A., Arav A., Livshitz L., Yakoby S., Moallem U., 2010. Effects of dietary fats differing in n-6:n-3 ratio fed to high-yielding dairy cows on fatty acid composition of ovarian compartments, follicular status and oocyte quality. J. Dairy Sci. 93, 529-545

Zeron Y., Sklan D., Arav A., 2002. Effect of polyunsaturated fatty acid supplementation on biophysical parameters and chilling sensitivity in ewe oocytes. Mol. Reprod. Dev. 61, 271-278 